\title{
Se otorga el Primer Premio de Teatro George Woodyard
}

El Premio de Teatro George Woodyard ha sido creado por quien escribe estas líneas con el apoyo del Departamento de Lenguas Clásicas y Modernas y su sección de Español de la Universidad de Connecticut en honor al Dr. George Woodyard, uno de los pioneros de la investigación sobre el teatro latinoamericano en la academia estadounidense. Los objetivos primordiales son estimular, apoyar, hacer accesibles y promover la creación de obras teatrales de alta calidad. El premio consiste de 2.500 dólares más gastos de viaje (ida y vuelta) a la Universidad de Connecticut, gastos de estadía por dos noches y publicación de la obra en Latin American Theatre Review. Para mayor información sobre las bases, fechas y fallos del premio se debe visitar la siguiente página electrónica: <http:// www.languages.uconn.edu/programs/awards.html>.

En esta primera edición se recibieron 106 obras provenientes de México, Argentina, Chile, Uruguay, Venezuela, Colombia, Cuba, Costa Rica y Estados Unidos. Luego de una deliberación sobre 11 obras seleccionadas, un destacado jurado de investigadores de la academia estadounidense integrado por Jacqueline E. Bixler (Virginia Tech University), Gastón Alzate (California State-Los Angeles) y Stuart A. Day (University of Kansas) decidió otorgar el I Premio de Teatro George Woodyard a la obra La culpa la tuvo el tranvía presentada bajo el seudónimo "Esmeralda." Una vez abierto el sobre sellado la autora resultó ser la argentina Cristina Merelli. El jurado destacó la complejidad, el agudo sentido del humor y la fuerza de las constantes tensiones dramáticas que se van revelando para crear una obra eficazmente elaborada que atrapa al lector desde sus primeros diálogos.

Cristina Merelli es directora, actriz, dramaturga, guionista de cine, cuentista y poeta. Ha participado en festivales en Argentina, Venezuela, Puerto Rico, España y Estados Unidos, y en años consecutivos sus obras han sido seleccionadas para participar en el ciclo argentino de Teatro X la Identidad. Tiene en su haber unas 35 obras teatrales entre las que se encuentran La gota que horada la piedra $\left(1^{\text {er }}\right.$ Premio de Teatro Nacional de Humor), Nidito de amor (Premio Proteatro), Teléfono (PremioTeatro X la Identidad 2001), Humo de leña verde (Premio Teatro X la Identidad 2002) y Al sur del paraíso ( $3^{\text {er }}$ Premio del Primer Concurso Iberoamericano de Textos Teatrales hacia una Nueva Dramaturgia otorgado por el CELCIT de Argentina).

La obra se va a publicar en el número 40.2 (Spring 2007) de LATR.

\section{Laurietz Seda}

University of Connecticut 